\title{
Pregnancy Characteristics and Women's Cardiovascular Health
}

\author{
Abigail Fraser, Janet M. Catov, Deborah A. Lawlor, \\ and Janet W. Rich-Edwards
}

\section{Introduction}

Growing evidence suggests that pregnancy is a "critical period" in a woman's life when her health development is especially sensitive to certain internal and external stimuli. As a normal response to pregnancy and in order to support the developing fetus, women become more insulin resistant and hyperlipidemic and experience an increase in blood pressure (BP; after an initial drop) and upregulation

This chapter contains a modified version of a previously published review and analysis of existing research that appeared in Epidemiologic Reviews. Reprinted with permission from:

Janet W. Rich-Edwards, Abigail Fraser, Deborah A. Lawlor, Janet M. Catov; Pregnancy Characteristics and Women's Future Cardiovascular Health: An Underused Opportunity to Improve Women's Health?. Epidemiol Rev 2014;36(1):57-70. doi: 10.1093/epirev/mxt006

AF and DAL work in a unit that receives infrastructure funding from the United Kingdom Medical Research Council (MC_UU_12013), and AF is funded by a United Kingdom Medical Research Council fellowship (MR/ M009351/1). A grant to DAL from the Wellcome Trust also supports this collaborative work (WT094529MA). JMC is funded by RO1HL103825 and K12HD43441. JRE is supported by an American Heart Association Founder's Grant (13GRNT17070022). The authors have no relevant disclosures, financial or otherwise.

A. Fraser $(\bowtie) \bullet$ D.A. Lawlor

Medical Research Council Integrative Epidemiology

Unit at the University of Bristol, University of

Bristol, Bristol, UK BS8 2BN

e-mail: abigail.fraser@bristol.ac.uk of coagulation factors and the inflammatory cascade (Sattar 2004). This is perhaps the prime example of health as an emergent property as it is one that enables the bearing of offspring and thus the perpetuation of humanity. While for a majority of women, this adaptation to pregnancy remains "healthy," in some women it develops into a complication of pregnancy such as gestational diabetes mellitus (GDM), preeclampsia, fetal growth restriction (FGR), and preterm delivery.

It has long been understood that pregnancy complications are important for the life course health development of offspring, but much less appreciated that these complications also have key implications for the long-term health development of the mother. An accumulating body of research has shown that these common pregnancy

\footnotetext{
J.M. Catov

Department of Obestetrics and Gynecology, University of Pittsburgh, Pittsburgh, PA 15213, USA

University of Pittsburgh, Department of Epidemiology, Pittsburgh, PA 15261, USA

Magee-Womens Research Institute, Pittsburgh, PA 15213, USA

J.W. Rich-Edwards

Connors Center for Women's Health and Gender

Biology, Brigham and Women's Hospital,

Boston, MA 02120, USA

Harvard Medical School, Boston, MA 02115, USA

Harvard School of Public Health,

Boston, MA 02120, USA
} 
complications predict the future risk of chronic diseases in women, including cardiovascular disease, diabetes, and breast cancer (Rich-Edwards 2009). In this chapter we use life course health development theoretical principles as a lens for an examination of the implications of pregnancy history for cardiovascular disease (CVD), a leading cause of female mortality (Oblast 1999; Yusuf et al. 2001).

Globally, one out of three women dies from CVD (Shah et al. 2009; Mathers et al. 2008). We do a worse job of recognizing and predicting CVD in women than in men, in part because CVD presents itself differently between the sexes (Mosca et al. 2011; Shaw et al. 2006). This has important implications for the prevention of CVD. Primary prevention, if applied to high risk populations early enough to avert the cumulative damage of chronic disease, can reduce CVD incidence (Scarborough and Weissberg 2011; Shay et al. 2012; MMWR 1989). In response to the growing appreciation that many preventive efforts start too late to be effective, there has been a call for "primordial prevention" - the prevention of the major CVD risk factors themselves (Labarthe 1999; Weintraub et al. 2011). In this context, pregnancy complications have the potential to be effective CVD risk "stress tests" to identify women who would most benefit from primordial or primary prevention efforts to reduce CVD risk (Sattar and Greer 2002). The concept of primordial prevention is consistent with the life course health development principle that health development is an emergent phenomenon and the best way to prevent future disease is to build health assets that have long-term salutary benefits.

On average, more than $80 \%$ of women in highincome countries bear at least one child (Martinez et al. 2012; OECD Family D 2014), as do upward of $90 \%$ of women in most lower- and middleincome nations (United Nations DoEaSA, Population Division 2009). A high proportion of women will, in the course of their reproductive career, have a pregnancy complicated by GDM, a hypertensive disorder of pregnancy, FGR macrosomia, or preterm delivery. The prevalence of any one of these conditions in any given pregnancy ranges from $2 \%$ to greater than $12 \%$. In one UK study, $36 \%$ of singleton pregnancies were compli- cated by at least one of these factors (Fraser et al. 2012). In the U.S. national Nurses' Health Study 2, we estimated that $29 \%$ of parous study participants have had one of these pregnancy complications. As reviewed below, each of these complications has been associated with roughly a twofold increase in the risk of CVD events. If $80 \%$ of women are parous and $30 \%$ of them have had a pregnancy complication predictive of CVD, then about $25 \%$ of women are at heightened risk for future CVD risk.

We begin with a review of the evidence for associations of parity and common pregnancy complications (low birth weight, fetal growth restriction, preterm delivery, hypertensive disorders of pregnancy, and GDM) with future CVD risk. We conducted MEDLINE searches for English-language cohort and case-control studies published in the peer-reviewed literature through December 2012, as described in detail elsewhere (Rich-Edwards et al. 2014). Whether pregnancy is a sensitive period in terms of cardiovascular health development across the life course and complications per se contribute to long term CVD risk, whether they simply unmask women with an underlying propensity for CVD, or whether both pathways are in play remains unclear. As suggested by life course health development, longitudinal studies are needed to untangle these temporal effects. In the second part of the chapter, we further explore the physiologic mechanisms that might explain the associations between pregnancy complications and CVD. Finally, we discuss the implications of these findings for future research as well as for health care design and policy.

\section{Associations of Parity and Pregnancy Complications with CVD Risk in Mothers}

\subsection{Parity and CVD}

Most (Green and Moser 1988; Ness et al. 1993) but not all studies (Steenland et al. 1996) have found a positive association between parity (number of children) and later CVD. In the largest study to date, the association was examined in 
1.3 million with a median follow-up time of 9.5 years (range 0-24) women using Swedish registry data (Parikh et al. 2010). Parity was associated with CVD in a J-shaped fashion, with two births representing the nadir of risk. Compared with women with two births, the multivariableadjusted hazard ratios (95\% confidence interval (CI)) for women with 0 and $\geq 5$ births were 1.11 (1.09-1.14) and 1.57 (1.52-1.64), respectively.

Desired family size may affect the shape of the parity-CVD risk distribution in different societies and is an example of how societal norms and social structures may affect health development and its determinants. In Sweden, the modal family size (two children) coincides with the nadir of maternal cardiovascular risk (Parikh et al. 2010). This suggests that many women who bore only one child suffered from secondary infertility, first pregnancy complications that precluded further pregnancies, or severe neonatal outcomes that discouraged further childbearing. To the extent that subfertility and severe pregnancy complications predict future CVD risk, they may explain the low-parity "hook" of the J-shaped association of parity and maternal CVD. The increase in CVD risk with increasing parity after two children may be the result of different phenomena. These include rival, but not mutually exclusive, theories that (1) adverse physiologic change accumulates over pregnancies; (2) adverse lifestyle habits accrue with more children; and/or (3) selection bias in which women at higher CVD risk opt for larger families. Thus, it is unclear whether the association of higher parity with CVD risk is causal or correlational.

Some insight into the association of parity with maternal CVD risk may be gleaned by examining the association of number of children with paternal CVD risk. Similar associations for mothers and fathers would suggest that the association between parity and maternal CVD is not causal, but is more likely a result of confounding by socioeconomic position and/or behaviors related to child-rearing. Three reports examined associations of number of children with CVD in fathers. In general, men who have fathered the most children appear to have small increased CVD risk, though this association is not always statistically significant and is weaker than the associations observed among mothers (Dekker and Schouten 1993; Lawlor et al. 2003; Ness et al. 1995). Adjustment for lifestyle factors tends to reduce the associations in both mothers and fathers (Lawlor et al. 2003; Catov et al. 2007a). These results suggest that the association between high parity and CVD in later life may be largely the result of socioeconomic position and/or behavioral risk factors associated with childrearing that are shared by both parents.

\subsection{Common Pregnancy Complications and CVD in Mothers}

Offspring birth weight predicts maternal lifespan (Catov et al. 2007a; Davey Smith et al. 1997, 2000a, b, 2007). Figure 1 presents the findings from studies that have examined associations of offspring birth weight or fetal growth - a function of birth weight and gestation length - with maternal CVD risk (Davey Smith et al. 1997, 2007, 2000a, b, 2005; Bellamy et al. 2007, 2011; Friedlander et al. 2007; Lykke et al. 2010a; Mongraw-Chaffin et al. 2010; Smith et al. 2001; Wikström et al. 2005; Fraser et al. 2012; Ness et al. 1993). One meta-analysis has calculated that, for every standard deviation (roughly $500 \mathrm{~g}$ ) higher birth weight of the firstborn child, maternal CVD mortality is decreased by 25\% (Davey Smith et al. 2007). It is unclear whether the inverse association of offspring birth weight with mortality is constant across the entire range of birth weight, as the association of high birth weight with maternal CVD risk varies by study. In some populations, the mothers of the largest infants ( $>4000 \mathrm{~g}$ or $>4500 \mathrm{~g}$ ) have the lowest risks of CVD (Davey Smith et al. 1997, 2000b), while in other populations there is an uptick in CVD risk for the mothers of macrosomic newborns (Davey Smith et al. 2007; Bonamy et al. 2011; Friedlander et al. 2007; Lykke et al. 2012). Given the strong associations of macrosomia with GDM and later type 2 diabetes (Metzger et al. 1993), the presence and magnitude of the association of large birth weight with future CVD risk may depend on the population prevalence of GDM and chronic diabetes during pregnancy (in other words, 


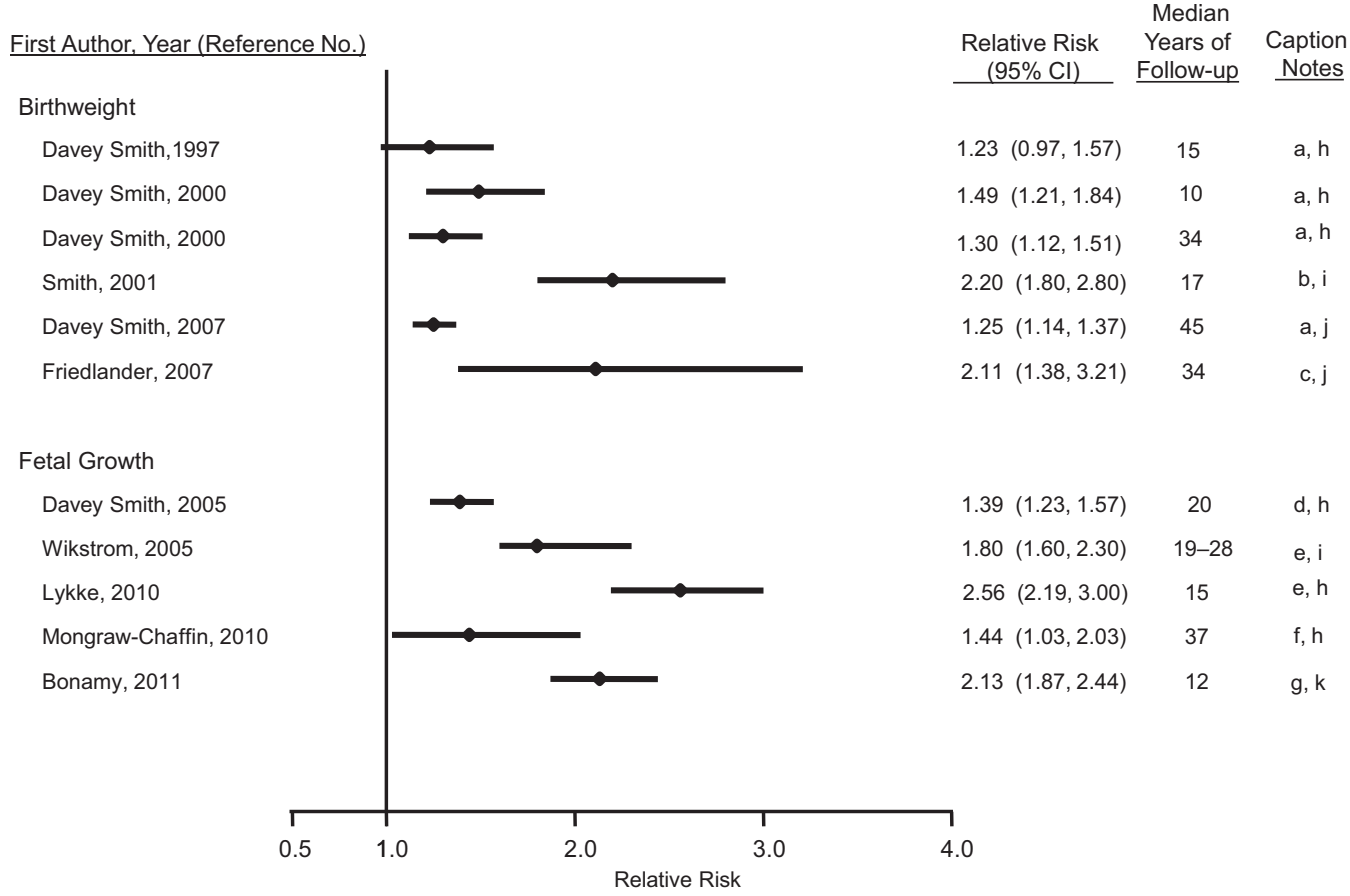

Fig. 1 Results from studies of offspring birth weight or fetal growth and relative risk of maternal cardiovascular disease (CVD). $a$ Per 1 standard deviation (SD) lower birth weight; $b$ lowest birth weight quintile compared to all others; $c<2500 \mathrm{~g}$ compared to 1500-3999 g birth weight; $d$ per 1 SD lower birth weight, adjusted for gesta- tional age; $e$ small for gestational age; $f$ intrauterine growth retardation; $g \sim 2$ SD below mean birth weight adjusted for gestational age; $h$ CVD mortality; $i$ coronary heart disease (CHD) events ; $j$ CHD mortality; $k$ CVD events ( $C I$ confidence interval)

maternal CVD risk (Bonamy et al. 2011; Lykke et al. 2012), as does gestation length (discussed below). In fact, the coincidence of restricted fetal growth and prematurity yields a more than threefold increased CVD risk (Bonamy et al. 2011). The curvilinear association of offspring birth weight with maternal CVD risk observed in many populations may be the product of competing pathological phenomena. At one end of the birth weight spectrum, the association of macrosomia with maternal CVD risk may be explained by underlying metabolic risk; at the other end of the spectrum, the association of low birth weight with maternal CVD risk may be driven by endothelial dysfunction and other pathologies associated with restricted fetal growth and preterm birth.

First offspring birth weight also predicts paternal CVD, although the magnitude of the positive association of offspring birth weight with paternal and gestation length. Fetal growth, represented as birth weight corrected for gestation length, predicts 
CVD risk is less than a third of that for the infant's mother (Davey Smith et al. 2007). The fact that the birth weight of their first child predicts CVD events in both parents suggests that shared lifestyle or environmental factors, such as cigarette smoking, might influence both the growth of the fetus and CVD risk in the parents and/or that pleiotropic genetic variants affect both growth and CVD risk. Birth weight is passed down through maternal and paternal lines (Lie et al. 2006), opening the possibility that paternal CVD/ fetal growth genes could affect both the pregnancy outcome and long-term chronic disease risk in the father (Freathy et al. 2007). However, the stronger association in mothers than in fathers suggests either parent-specific genomic imprinting or-as seems more parsimonious-that maternal health during pregnancy affects fetal growth and is a marker of her future CVD risk.

Preterm delivery ( $<37$ weeks' gestation) accounts for $6-12 \%$ of deliveries in the developed world (Beck et al. 2010). The hazard ratios for CVD associated with total preterm delivery are depicted in Fig. 2 and are on the order of 1.3-2.6 for births $<37$ completed weeks compared with term births (Davey Smith et al. 2000b, 2005; Bonamy et al. 2011; Lykke et al. 2010a, b; Smith et al. 2001; Wikström et al. 2005; Catov et al. 2010a; Irgens et al. 2001; Nardi et al. 2006; Pell et al. 2004; Rich-Edwards et al. 2012). There is a greater range of relative risk when distinct preterm phenotypes are examined separately. While most preterm deliveries follow spontaneous labor or preterm premature rupture of membranes, a significant and growing fraction results from medically induced labor or Caesarean section without labor. The chief reasons for these medically indicated deliveries include preeclampsia and FGR, both of which have been associated with increased maternal CVD risk. In studies that have distinguished them, hypertensive preterm deliveries consistently have a stronger association with maternal CVD outcomes than do normotensive preterm deliveries, though the latter are still associated with a 1.2- to threefold increased risk compared with term deliveries (Catov et al. 2010a; Irgens et al. 2001). In the two studies that have contrasted CVD risk among mothers with spontaneous versus indicated preterm deliveries (Rich-Edwards et al. 2012; Hastie et al. 2011a), indicated delivery was associated with higher risks of CVD mortality than spontaneous preterm delivery. Nevertheless, spontaneous preterm delivery-compared with term delivery-was associated with doubling of CVD risk (RichEdwards et al. 2012; Hastie et al. 2011a).

Unlike the associations of parity or birth weight with paternal CVD risk, two studies (Davey Smith et al. 2005; Irgens et al. 2001) have reported that preterm delivery is not associated with paternal risk of CVD, implying that the association of preterm delivery with maternal CVD risk is not the product of a high-CVD risk lifestyle or genetic variants shared between both parents and their offspring. Of relevance, preterm birth risk appears to be passed only through the maternal line (Wilcox et al. 2008). These observations suggest that maternal intrauterine environment and health determine the risk of preterm delivery and explain its association with maternal CVD risk, rather than shared lifestyle or environment of the mother and father.

Gestational diabetes mellitus is a common and growing pregnancy complication that affects as many as $5 \%$ of pregnancies. It is well established that women with GDM are at increased risk of developing diabetes later in life (Bellamy et al. 2009); between $3 \%$ and $70 \%$ of women with a history of GDM will develop type 2 diabetes within three decades of the pregnancy (Kim et al. 2002), with a meta-analysis of 675,455 women finding a sevenfold increase in risk of later type 2 diabetes (Bellamy et al. 2009). Type 2 diabetes is an important CVD risk factor, having a markedly higher relative and absolute association with CVD in women than it does in men (Sarwar et al. 2010). Given these associations, it seems self-evident that a history of GDM would be associated with increased CVD risk. However, due largely to the fact that GDM screening during pregnancy was neither routine nor standardized until recent decades, there are few cohorts with long enough follow-up of screened populations to detect CVD incidence or mortality among women with a history of GDM (Shah et al. 2008; Carr et al. 2006). These are displayed in Fig. 3. The only large population-based study of this topic is a 


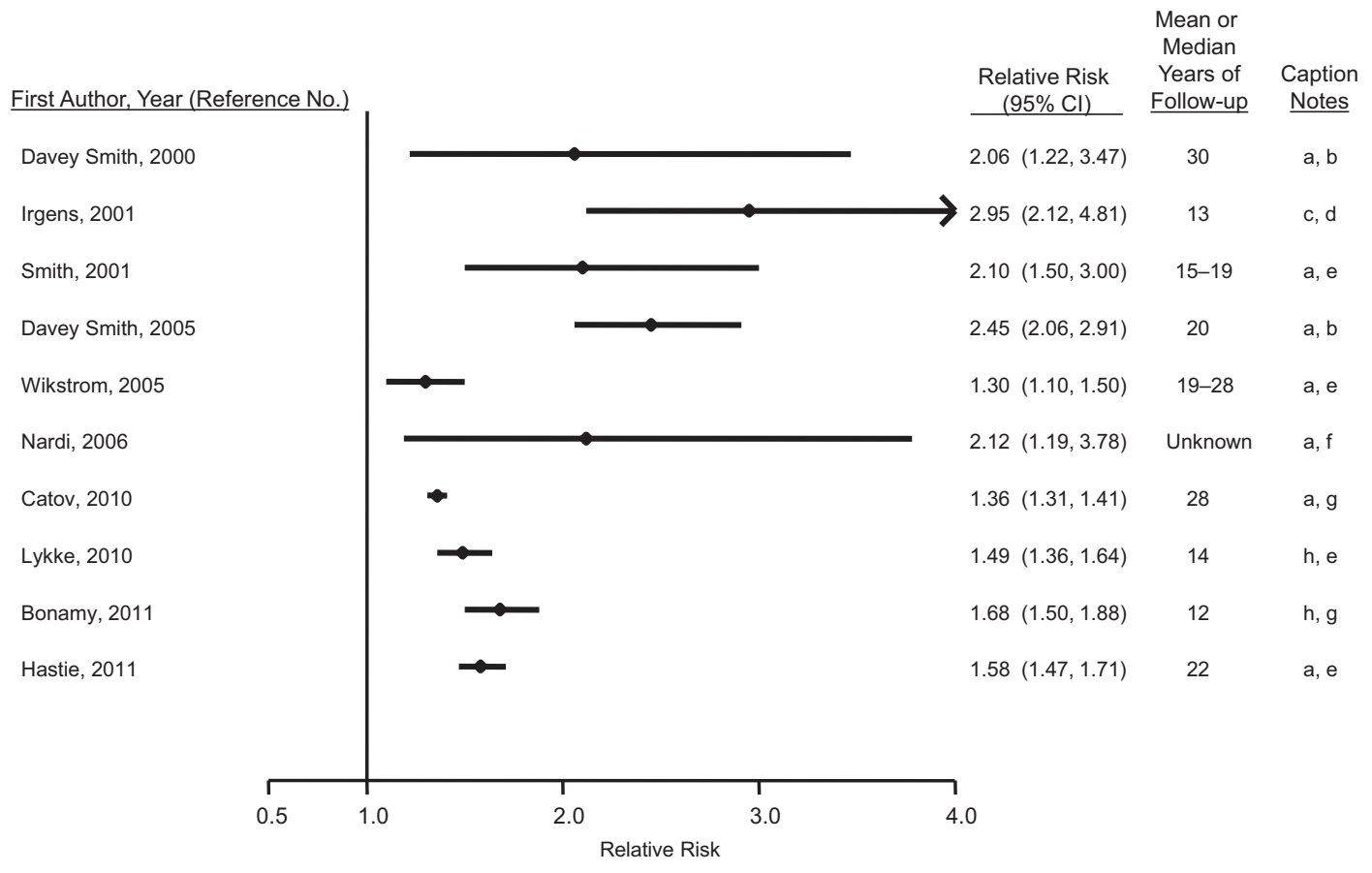

Fig. 2 Results from studies of preterm delivery and relative risk of maternal cardiovascular disease (CVD). $a<37$ weeks' gestation weeks compared with term; $b$ CVD mortality; $c<37$ weeks' gestation length compared with term normotensive pregnancies; $d$ CVD mortality, excluding

record linkage study conducted in Ontario, Canada, with a median follow-up of 11.5 years (Shah et al. 2008). In that study, a history of GDM was associated with a greater risk of hospital admission for acute myocardial infarction, coronary bypass, coronary angioplasty, stroke, or carotid endarterectomy (hazard ratio $(\mathrm{HR})=1.71 ; 95 \% \mathrm{CI}, 1.08-2.69$ ) Upon adjustment for diabetes after pregnancy, the association was attenuated toward the null (adjusted HR, 1.13; 0.67-1.89). A smaller, cross-sectional study found that women with a history of GDM had a higher CVD risk than women without a history of GDM (adjusted OR $=1.85,1.21-2.82$ ) and experienced CVD events 7 years earlier, on average (Carr et al. 2006).

Lesser degrees of antepartum hyperglycemia have also been associated with an elevated risk of subsequent diabetes and CVD. In the Ontario study, women with evidence of elevated glycemia short of GDM criteria were at an increased risk of diabetes $(\mathrm{HR}=2.56,2.28-2.87)$ stroke mortality; $e$ coronary heart disease (CHD) events; $f$ myocardial infarction; $g$ CVD events; $h$ 32-36 weeks' gestation length compared with term (CI confidence interval)

(Retnakaran and Shah 2009a) and CVD (HR $=1.19,1.02-1.39)$ (Retnakaran and Shah 2009b) compared to normoglycemic women.

Hypertensive disorders of pregnancy (HDPs) are common pregnancy complications that presage CVD. Preeclampsia, the combination of hypertension and proteinuria, affects approximately $2-5 \%$ of pregnancies, with a predominance among first pregnancies (Fraser et al. 2012; Wallis et al. 2008; North et al. 2011). Estimates of the prevalence of gestational hypertension, new-onset hypertension without proteinuria, vary from 3\% to 14\% (Fraser et al. 2012; Wallis et al. 2008; Roberts et al. 2005). Women with a history of preeclampsia have roughly fourfold higher incidence of hypertension and twofold elevated risks of heart disease, stroke, and venous thromboembolism (Bellamy et al. 2007; McDonald et al. 2008). Two systematic reviews, one of cohort studies $(n=25)$ and the other of both cohort $(n=10)$ and case-control $(n=5)$ studies, 


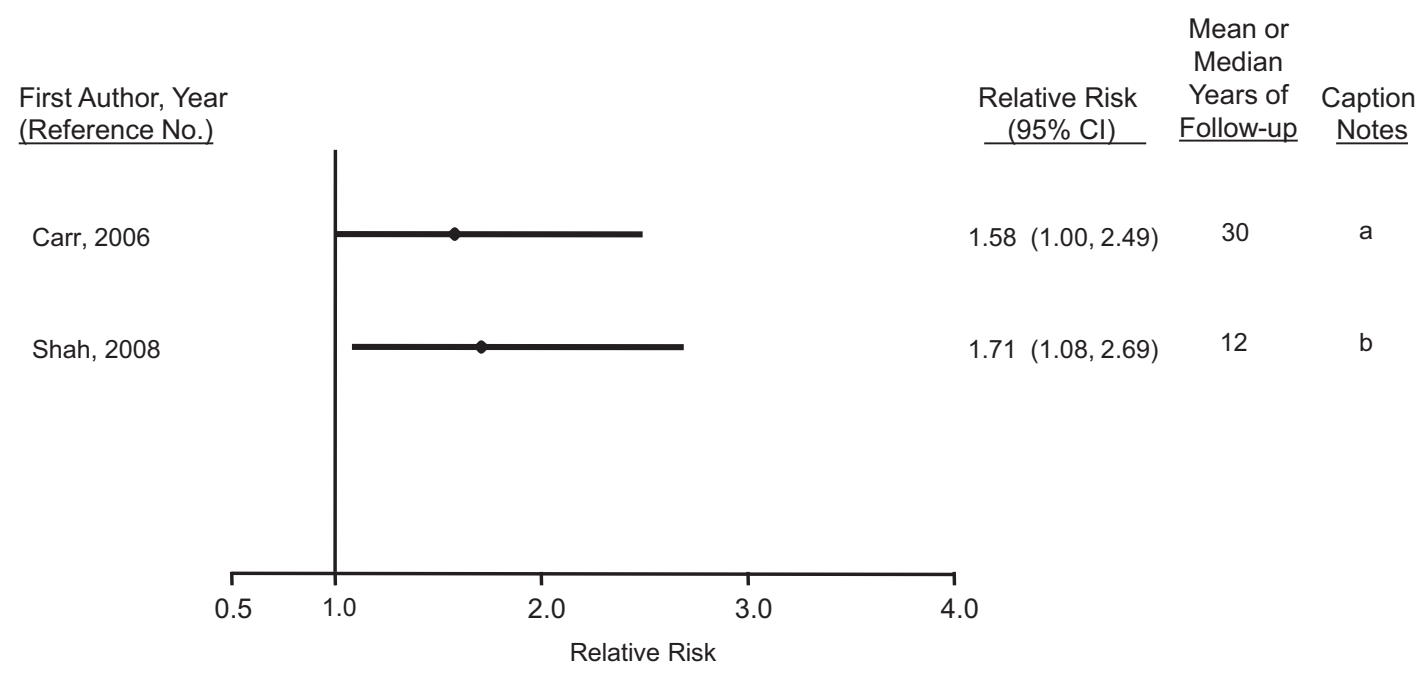

Fig. 3 Results from studies of gestational diabetes mellitus and relative risk of maternal cardiovascular disease (CVD). $a$ Self-reported coronary artery disease, $b$ CVD events (CI confidence interval)

have both reported a doubling of risk for different measures of CVD comparing women with preeclampsia to normotensive women over a median of 10-12-year follow-up (Bellamy et al. 2007; McDonald et al. 2008). Figure 4 depicts the relative risk of coronary heart disease (CHD) and CVD outcomes among mothers with a history of preeclampsia (Mongraw-Chaffin et al. 2010; Smith et al. 2001; Wikström et al. 2005; Irgens et al. 2001; Funai et al. 2005; Hannaford et al. 1997; Jónsdóttir et al. 1995; Kestenbaum et al. 2003; Lin et al. 2011; Lykke et al. 2009; Wilson et al. 2003).

Publications from three cohort studies published since those reviews give some insight into the onset and duration of CVD risk following HDP (Mongraw-Chaffin et al. 2010; Smith et al. 2001; Lin et al. 2011; Lykke et al. 2009). In a short-term follow-up of over 1,000,000 pregnancies in Taiwan, women with preeclampsia/ eclampsia were at double the risk of major CVD from the third trimester of pregnancy up to three years postpartum, with particularly high relative risks for stroke $(\mathrm{HR}=14.5,1.3-165.1)$ and myocardial infarction $(\mathrm{HR}=13.0,4.6-6.3)$ (Lin et al. 2011). While these results suggest a high relative risk immediately following HDP, the confidence intervals are wide, and the absolute risk of CVD events is very small at this age, so that this immediate risk is unlikely to account for a large number of CVD events. The Child Health and Development Study in California has provided some of the longer follow-up; over 37 years after pregnancy, women with a history of preeclampsia in any pregnancy had double the risk of CVD death $(\mathrm{HR}=2.14 ; 1.29-3.57)$ (Mongraw-Chaffin et al. 2010). This doubling of risk is consistent with studies with shorter duration of follow-up. Considering the exponential increase in the absolute numbers of CVD events with increasing age, this suggests that the elevated risk of CVD among women with a history of HDP is not limited to the early years postpartum.

Thus, studies repeatedly report a doubling of CVD risk among women with a history of preeclampsia and suggest lesser degrees of excess risk among women with a history of gestational hypertension, despite the strong association of gestational hypertension with development of chronic hypertension (Lykke et al. 2009). The combination of preterm delivery and preeclampsia-a likely marker of the severity of preeclampsia-is a particularly potent predictor of CVD risk. Compared to normotensive term pregnancies, women delivering preterm preeclamptic pregnancies have very high relative risks of future 


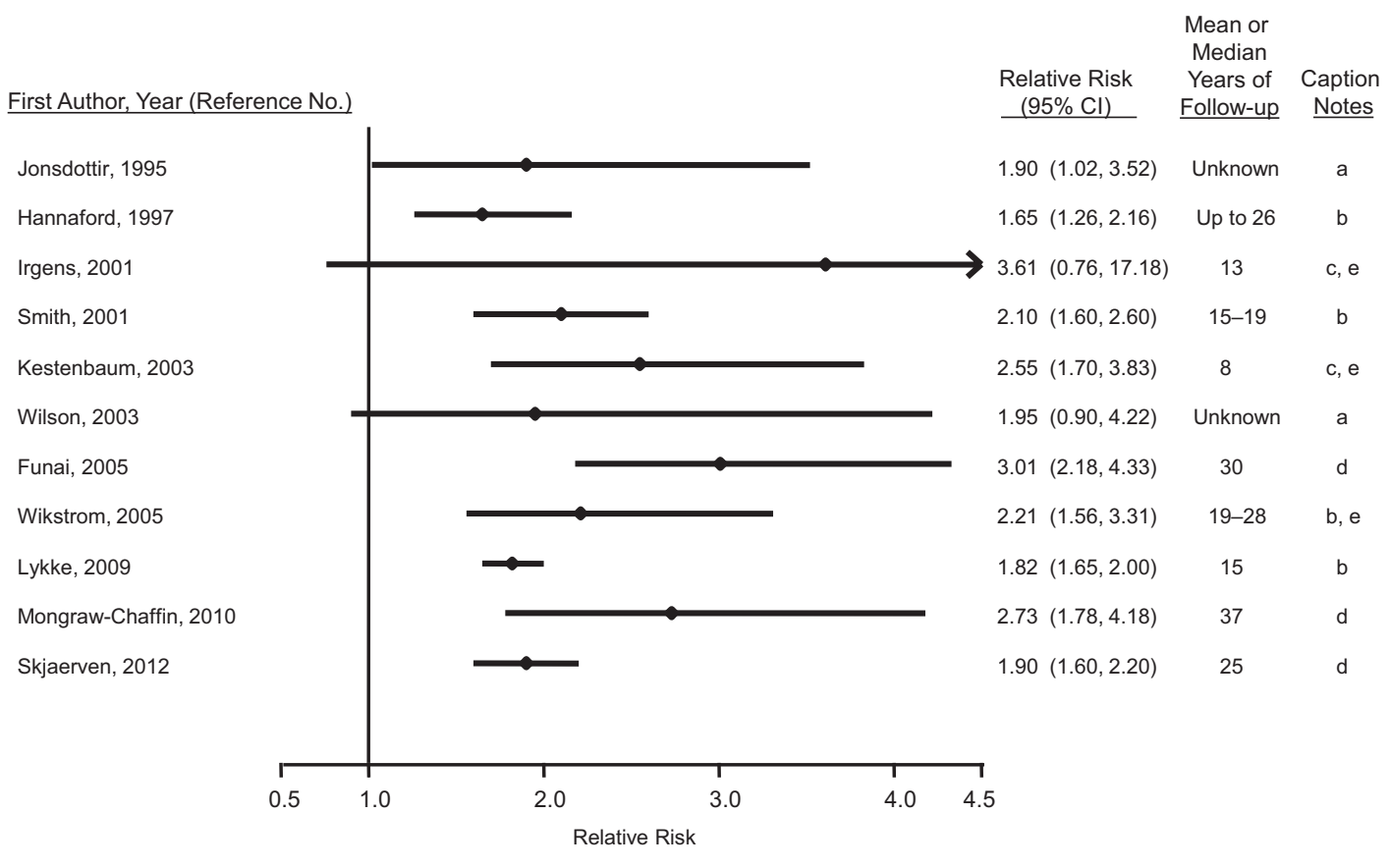

Fig. 4 Results from studies of hypertensive disorders of pregnancy and relative risk of maternal cardiovascular disease (CVD). $a$ Coronary heart disease (CHD) mortality, $b$ CHD events, $c$ CVD events, $d$ CVD mortality, $e$ composite estimate provided by Bellamy review (18). A 2011 study by Lin (62) reported a relative risk of 23.0 (95\% confidence interval (CI), 5.1-103.7) for CVD events (except stroke) during pregnancy and up to three years after delivery. We omitted that study from the figure so that we could keep the relative risk scale consistent across figures
CVD ranging from 2.5 to 9.5. (Mongraw-Chaffin et al. 2010; Smith et al. 2001; Lin et al. 2011; Skjaerven et al. 2012)

\subsection{Recurrent Pregnancy Complications, Last Pregnancy Complications, and Maternal CVD Risk}

Much of the literature is based on first pregnancies, precluding examination of the association of recurring pregnancy complications with CVD risk. There is evidence that recurrent preeclampsia (Lykke et al. 2009) and preterm delivery(Catov et al. 2010a; Lykke et al. 2010b) are associated with a greater risk of CVD than a single complicated pregnancy in multiparous women. Although the association of recurrent GDM with CVD risk has not been studied, after a first GDM pregnancy, each subsequent GDM pregnancy has been associated with a modestly increased risk of type 2 diabetes (adjusted $\mathrm{HR}=1.16,1.01-1.34)$ and each non-GDM pregnancy with a reduced risk of diabetes ( $\mathrm{HR}=0.34$, 0.27-0.41) (Retnakaran et al. 2011). In fact, this highlights an intriguing pattern that is emerging with respect to last births: having preeclampsia (Skjaerven et al. 2012), preterm delivery (RichEdwards et al. 2012), or GDM (Retnakaran et al. 2011) in the last pregnancy appears to be associated with especially high risk of future CVD in mothers. Perhaps reflecting the same phenomenon, women who have one preterm delivery and one term delivery in their first two births appear to be at higher risk of CHD if the preterm delivery was the second birth (Catov et al. 2010a; Lykke et al. 2010b). This suggests that pregnancy complications severe enough to contraindicate or discourage a subsequent pregnancy may be particularly potent predictors of future CVD risk. 


\section{Physiological Mechanisms Linking Pregnancy Complications to Maternal CVD Risk}

Pathways that link pregnancy exposures to later life CVD are not well understood. Considerable evidence supports the existence of common predisposing factors for both pregnancy complications and CVD risk suggesting that pregnancy complications can be thought of as a failed stress test, with pregnancy being the stressor. There have been almost no studies examining the alternative that pregnancy complications might cause increased CVD risk. To address this issue, we summarize evidence that compares CVD risk before, during, and after pregnancies with and without complications.

\subsection{Cardiovascular Risk Factors Preceding Pregnancy Complications}

Higher prepregnancy blood pressure is a risk factor for preeclampsia (Magnussen et al. 2007) and preterm delivery (Catov et al. 2013). Chronic hypertension has a well-established relation to increased risk of preeclampsia-known as "superimposed" preeclampsia. Even within the normotensive range, there is a positive doseresponse association of prepregnancy systolic and/or diastolic blood pressure with preeclampsia, (Magnussen et al. 2007) and women who develop hypertensive disorders of pregnancy have higher blood pressure at 8 weeks' gestation than normotensive (Macdonald-Wallis et al. 2012). Preexisting hypertension has also been associated with FGR, especially in cases that were also preterm (Catov et al. 2008a). Risks for these complications also rise with increasing maternal age, suggesting that the aging endothelium may less successfully adapt to the profound vascular demands of pregnancy.

Prepregnancy lipid concentrations are also associated with pregnancy complications and offspring birth weight; the nature of the associa- tion varies with the pregnancy outcome in question. Lipid profiles consistent with elevated CVD risk, including higher prepregnancy triglyceride levels, total cholesterol, and lower HDL cholesterol, have been associated with preeclampsia and preterm delivery in the study in Norway (Magnussen et al. 2007, 2011). The US Coronary Artery Risk Development in Young Adults Study (CARDIA) found a curvilinear association of prepregnancy cholesterol levels with risk of delivering preterm (Catov et al. 2010b). With respect to fetal growth, women with a more atherogenic lipid profile may bear larger infants (Romundstad et al. 2007); this suggests that the association of low birth weight - at least the fetal growth component of low birth weight-with maternal CVD risk may not operate via dyslipidemia.

Prepregnancy adiposity and glucose/insulin dysregulation is strongly implicated in the etiology of GDM, based on the observation that women with GDM tend to have a family history of type 2 diabetes and higher body mass index (BMI) before pregnancy (Solomon et al. 1997), as well as higher levels of glucose and insulin and lower levels of adiponectin before the onset of the midpregnancy hyperglycemia that defines GDM (Nanda et al. 2011; Riskin-Mashiah et al. 2010; Sacks et al. 2003; Williams et al. 2004). Higher BMI and family history of diabetes are also associated with increased risk of preeclampsia (Qiu et al. 2003; O’Brien et al. 2003). The risk of preeclampsia doubles with every $5-7 \mathrm{~kg} / \mathrm{m}^{2}$ increase in body mass index before pregnancy (O'Brien et al. 2003).

Thus, subclinical elevations in the classic CVD risk factors of blood pressure, lipid levels, elevated BMI, and glucose/insulin dysregulation appear to predate both preeclampsia and GDM. Less clear is the extent to which CVD risk factors precede spontaneous preterm deliveries or FGR in normotensive pregnancies. Furthermore, the roles of prepregnancy inflammatory and coagulation factors with respect to pregnancy complications remain to be elucidated, despite the importance of these systems for both reproduction and CVD risk (Romero et al. 2007). 


\subsection{Cardiovascular Risk Factors During Pregnancy}

\subsubsection{Cardiovascular Adaptation in Normal Pregnancy}

In normal gestation, maternal blood volume increases progressively from 6 to 8 weeks' gestation, peaking at an increase of $45 \%$ by 32 weeks (Monga and Creasy 1994). Cardiac output increases by $30-50 \%$, with half of this increase occurring very early in gestation. Pulse rate increases $17 \%$, and there are striking alterations in renal physiology. Although the insulin response to glucose is augmented in early pregnancy, insulin resistance emerges in the second half of pregnancy (Butte 2000). In addition, cholesterol and triglyceride profiles change after gestation week 9 to support steroid synthesis and fetal growth (Butte 2000). In uncomplicated pregnancy, there is a tendency for low-density lipoprotein (LDL) to shift across gestation from large, buoyant particles to smaller, denser, and more atherogenic particles (Hubel et al. 1998a). Fat is accumulated during the second trimester and then mobilized to support the dramatic fetal growth of the third trimester (Herrera 2000).

\subsubsection{Cardiovascular Risk Factors During Pregnancy Complications}

Vascular and endothelial dysfunction is characteristic of pregnancies complicated by preeclampsia or growth restriction. Placental underperfusion is common, and there are elevated markers of endothelial dysfunction in the maternal circulation. Women with hypertensive disorders of pregnancy demonstrate increased resistance in the uterine arteries (Ducey et al. 1987; Campbell and Griffin 1983), vascular stiffness, and impaired endothelial response (Savvidou et al. 2003, 2011). In addition, placental vascular lesions indicative of failed spiral artery remodeling, ischemia, or hemorrhage have also been reported in cases of both medically indicated and spontaneous preterm birth (Kelly et al. 2009).

During pregnancy, lipid aberrations accompany several pregnancy complications. Again, the direction of the associations appears to depend on the nature of the pregnancy complication. The dyslipidemias associated with atherosclerosis (hypertriglyceridemia, hypercholesterolemia, elevated free fatty acids, and excess oxidized LDL) are frequently seen during preeclampsia ... (Clausen et al. 2001; Hubel et al. 1996, 1998b; Sattar et al. 1997). There is also emerging evidence to suggest that this atherogenic lipid profile is associated with both spontaneous and indicated preterm births (Edison et al. 2007; Catov et al. 2007b). Similarly, women with GDM exhibit elevations in triglycerides and, less consistently, total cholesterol and LDL during pregnancy (Enquobahrie et al. 2005). On the other hand, low maternal total and LDL-cholesterol concentrations appear in the third trimester in pregnancies complicated by FGR (Sattar et al. 1999). Placental studies are conflicting, with some suggesting reduced expression of lipoprotein receptors in placentas from FGR vs. appropriate weight for gestational age births (Wadsack et al. 2007) and others suggesting overexpression of these receptors (Stepan et al. 1999). FGR studies are hampered by nonstandard phenotyping, and thus findings may represent differing levels of severity. Despite these limitations, these data suggest that extremes of lipid concentrations are associated with adverse pregnancy outcomes. Longitudinal studies are needed to better understand how the relative contributions of low or high cholesterol are related to failed or compensatory lipid adaptation required to optimize fetal growth.

Metabolic dysregulation in pregnancy defines GDM and is a strong risk factor for preeclampsia; there is considerable overlap of the two conditions, with twice the rate of preeclampsia in diabetic versus nondiabetic pregnancies (Ostlund et al. 2004). However, GDM has only a modest association with spontaneous preterm birth (Hedderson et al. 2003). Higher early-pregnancy BMI is associated with increased risk of HDP and GDM (Solomon et al. 1997; O'Brien et al. 2003; Lawlor et al. 2012), but with reduced risk of SGA and spontaneous preterm birth in most studies (Smith et al. 2007).

Systemic inflammation during pregnancy may be important in the pathogenesis of several preg- 
nancy complications. Elevated serum levels of C-reactive protein and/or leukocytes have been detected in women who experience GDM, FGR, and both spontaneous and indicated preterm deliveries (Catov et al. 2007c; Ernst et al. 2011; Freeman et al. 2004; Pitiphat et al. 2005; Wolf et al. 2001). However, neither mid-gestation circulating levels of C-reactive protein nor proinflammatory cytokines have proven to have prognostic value for specific pregnancy outcomes (Curry et al. 2007; Gammill et al. 2010).

Normal pregnancy is a state of hypercoagulability, and complications such as preeclampsia and preterm birth are characterized by particularly high biomarkers of an activated fibrinolytic cascade, as well as perhaps an impaired ability to mount this response appropriately (Catov et al. 2008b; Hackney et al. 2010; Heilmann et al. 2007). It has been hypothesized that aberrations in the cross talk between inflammation and the coagulation cascades could contribute to the pathophysiology of these pregnancy complications (Girardi 2011).

\subsection{Cardiovascular Risk Factors After Pregnancy}

\subsubsection{Enduring Cardiovascular Impact of Normal Pregnancy}

Most of the cardiovascular adaptations to normal pregnancy resolve in the postpartum period, although there are some detectable and lasting pregnancy effects. Blood pressure is modestly decreased in the postpartum period after a first uncomplicated pregnancy (Hackney et al. 2010). However, other lingering effects are not as salutary. Importantly, women retain, on average, 0.5-5.0 kg of weight following each pregnancy (Heilmann et al. 2007; Girardi 2011). Lactation may help resolve the cardiometabolic adaptations and fat accumulation associated with pregnancy (Agatisa et al. 2004; Berends et al. 2008; Catov et al. 2011).

The first birth may be a sentinel marker for complications in later pregnancies and future CVD risk (Lauenborg et al. 2005; Meyers-Seifer and Vohr 1996; Verma et al. 2002). Several fac- tors distinguish first births. First, longitudinal studies suggest that the lasting blood pressure and lipid changes associated with pregnancy occur after first but not subsequent births (Hackney et al. 2010). In addition, first births are at higher risk for the major obstetric complications of preterm delivery, HDP, FGR, and stillbirth. Women with any of these complications are at higher risk in subsequent pregnancies for recurrence of the same complication as well as the onset of other complications. Importantly, complications during a first pregnancy impact the likelihood of having a subsequent pregnancy. As noted above, complications in a last pregnancy appear to be associated with especially high relative risks of CVD events. Thus, health status of the first and last pregnancies may be particularly telling of future maternal health.

The cumulative effect of these adaptations and resolutions and risks may contribute to the above-noted J-shaped association between parity and maternal CVD risk, with lowest risk for women who have delivered two infants. It is not clear whether pregnancies exert a cumulative cardiovascular burden with increasing parity, whether higher-order pregnancies at more advanced maternal age exert more cardiovascular risk, or whether women at high cardiovascular risk bear more children.

\subsubsection{Cardiovascular Risk After Pregnancy Complications}

The association of vascular and endothelial dysfunction with pregnancy complications continues after delivery. Women with preeclampsia have impaired endothelial function after pregnancy (Agatisa et al. 2004). This may also be true, although to a lesser extent, of women who deliver small babies due to FGR or preterm delivery. For example, lower offspring birth weight is associated with higher maternal blood pressure in the years after pregnancy (Davey Smith et al. 2005). Some (Catov et al. 2013; Berends et al. 2008) but not all (Catov et al. 2011) studies report higher blood pressure and atherosclerotic carotid vessel remodeling among women who have delivered an FGR neonate. Although studies are not unanimous (Macdonald- 
Wallis et al. 2012; Lauenborg et al. 2005), women with a history of GDM are more likely to have hypertension (Meyers-Seifer and Vohr 1996; Verma et al. 2002), vascular dysfunction (Heitritter et al. 2005), impaired endotheliumdependent vasodilatation (Anastasiou et al. 1998), and higher carotid artery intima-media thickness (Tarim et al. 2006). These differences are not fully explained by the higher BMI typical of women with a history of GDM.

Studies of lipid profiles after pregnancies complicated by preeclampsia are consistent with increased atherogenesis risk, including consistently reported higher total cholesterol, LDL cholesterol, and triglycerides, although these differences are not always statistically significant (Fraser et al. 2012; Manten et al. 2007; Hubel et al. 2008; Laivuori et al. 1996; Magnussen et al. 2009; Romundstad et al. 2010; Sattar et al. 2003; Smith et al. 2009). Associations of reduced HDL cholesterol after preeclampsia have been reported by some (Fraser et al. 2012; Magnussen et al. 2009; Romundstad et al. 2010; Smith et al. 2009) but not all (Manten et al. 2007; Laivuori et al. 1996; Sattar et al. 2003) studies. One study has reported dyslipidemia among women with a history of spontaneous and indicated preterm births (Catov et al. 2011). Some (Lauenborg et al. 2005; Meyers-Seifer and Vohr 1996; Verma et al. 2002; Di Cianni et al. 2007) but not all (Schwarz et al. 2009) have reported elevated total cholesterol, LDL cholesterol, and/or triglycerides in women with a history of GDM. As with the studies of lipid concentrations before and during pregnancy, studies of lipid concentrations in women in the years after FGR are conflicting, with some reporting hyperlipidemia (Kanagalingam et al. 2009) and others reporting no differences compared to women with uncomplicated births (Catov et al. 2011).

It is now firmly established that women with a history of GDM have a manifold higher risk of developing type 2 diabetes than women with normoglycemic pregnancies (Bellamy et al. 2009). It is less widely appreciated that women with a history of preeclampsia are also at high risk of type 2 diabetes. After preeclampsia, mothers are three times more likely to develop diabetes within 16 years (Lykke et al. 2009), an observation bolstered by evidence of dysregulated glucose and insulin, as well as insulin resistance as early as 2 years after preeclamptic pregnancy (Fraser et al. 2012; Manten et al. 2007; Laivuori et al. 1996; Magnussen et al. 2009; Smith et al. 2009; Wolf et al. 2004). However, not all pregnancy complications are associated with risk of future metabolic disorder: in the Nurses' Health Study 2, although 2\% of women who delivered a very preterm infant $(<32$ weeks' gestation) had a 35\% higher risk of developing type 2 diabetes, moderate preterm delivery was not associated with increased diabetes risk (James-Todd et al. 2010).

After pregnancy, plasma C-reactive protein is elevated among women with prior eclampsia and indicated preterm births suggesting that systemic low-grade inflammation may link some adverse pregnancy outcomes and later CVD (Hastie et al. 2011b; Hubel et al. 2006). Several studies have documented higher C-reactive protein levels among women with a history of GDM (Heitritter et al. 2005; Di Cianni et al. 2007; Winzer et al. 2004). Although inflammation seems a likely culprit to explain the association of spontaneous preterm delivery with CVD risk, the only study to date that has examined this question has reported no differences in plasma C-reactive protein levels of women with a history of spontaneous preterm delivery compared to term delivery (Hastie et al. 2011b).

Women with a history of pregnancies complicated by preeclampsia may maintain a procoagulation state in the years after pregnancy, predisposing them to vascular and thrombotic events (Portelinha et al. 2009), although this pathway is less studied than others linking pregnancy complications to maternal CVD risk.

Thus, the associations of pregnancy complications with future CVD events in women are likely explained, at least in part, by their associations with classic CVD risk factors of hypertension, dyslipidemia, type 2 diabetes, and perhaps inflammation and thrombosis, which are evident before, during, and after such complicated pregnancies. Pregnancy provides a challenge to women's cardiovascular system, and pregnancy 
complications may serve as precursors, i.e., early indications that a woman is on a high-CVD risk trajectory, before these classic CVD risk factors are clinically detected. That said, this trajectory is complex and likely to be nonlinear. Given that most pregnancies occur in early adulthood, long before most CVD events occur, there is ample opportunity to influence that trajectory by recognizing that health develops continuously over the lifespan and that health development is a process resulting from the ongoing interactions between person and environment.

\section{$4 \quad$ Recommendations for Future Research}

\subsection{Major Themes and Findings}

The associations of pregnancy complications with CVD events are remarkably consistent.

Several pregnancy complications are more common among racial minority groups, who are also at higher risk of metabolic and cardiovascular disease. Although untested, the use of pregnancy complication history to screen women for targeted CVD prevention has potential to improve public health, given the magnitude of the associations, the prevalence of the pregnancy complications, and the importance of CVD in women. Pregnancy complications occur early enough in a woman's life course to offer a significant meaningful "runway" for primordial CVD prevention by lifestyle intervention and primary prevention by statins and antihypertensive drugs. In 2011, both the American Heart Association and the European Society of Cardiology included histories of preeclampsia and (in the case of the American Heart Association) GDM as part of CVD risk assessment that would trigger closer monitoring and control of CVD risk factors (Mosca et al. 2011; Regitz-Zagrosek et al. 2011). Pregnancy appears to be a critical transition period for a woman that stresses her cardiovascular system in ways that may shed light on future disease risk.

\subsection{Research Priorities}

(a) Epidemiologic research

- Establishing whether pregnancy complications per se contribute to CVD risk

We need to establish whether pregnancy complications act as stress tests to unmask women who are already at increased risk of CVD in later life and/or whether (and which) pregnancy complications have a causal, direct contribution to a woman's CVD risk. If pregnancy complications per se contribute to CVD risk independently of prepregnancy cardiovascular health, prevention strategies and treatment of pregnancy complications could be important not only for women and their offspring during the pregnancy but also later in life.

(b) Mechanism research

- Identifying mechanistic pathways to pregnancy complications and CVD

Should epidemiologic evidence suggest that pregnancy complications are causally associated with greater future CVD risk, it will be important to ascertain the underlying pathways responsible for these effects in order to identify potential treatment pathways. Gaining better understanding of the mechanisms underlying pregnancy complications themselves will also be important in informing prevention strategies.

(c) Translational research

- Improving risk stratification

Irrespective of whether pregnancy complications causally contribute to future CVD risk, a key question is the extent to which pregnancy history can be used to improve CVD risk scoring systems for women, such as the Framingham Risk Score. At present, these scoring systems are of debatable utility for women under age 70 (Greenland et al. 2010), and addition of pregnancy complications to prediction at these relatively younger ages may be particularly important. Several pregnancy 
complications are more common among racial minority groups, who are also at higher risk of metabolic and cardiovascular disease. Pregnancy history may be of particular importance in identifying risk in these groups.

- Establishing strategies to mitigate future CVD risk in women with pregnancy complications

If pregnancy complications are useful for early CVD risk prediction, the next question is whether earlier risk identification - as early as at the time of pregnancy-is a cost-effective way of reducing future risk. To do so it is important to examine whether women who experienced pregnancy complications should undergo more intense or earlier screening and monitoring in the postpartum years in order to determine whether they cross thresholds for treatment (e.g., with statins) earlier than women without pregnancy complications. We would also need to test the extent to which different lifestyle or pharmacologic preventions are effective at preventing future CVD in young or middle-aged women with a history of pregnancy complications. Key to this is identifying stages in the lifespan when women are (or are not) receptive to CVD prevention, including the postpartum year.

\subsection{Data and Methods Development Priorities}

(a) Importance of linking research across life stages: need for extended follow-up of women with known reproductive histories

The bulk of the research associating pregnancy history to CVD risk is derived from the linkage of large, often national, vital statistics registries for birth, hospitalization, and mortality statistics. These exercises have yielded consistent associations of pregnancy complications with CVD risk. However, as most registries were founded in the 1950s or 1960s, the longest-running has been able to follow women only into the early postmenopausal years. The data on GDM are further limited by the lack of consistent methods for screening and diagnosing
GDM. Further follow-up will determine the extent to which the associations of pregnancy complications are maintained into the age range at which CVD events are most common in women. In the meantime, the stratification of risk by time since pregnancy is a helpful way to examine the extent to which risk associated with pregnancy complications changes over time (Hastie et al. 2011a). Although relative risk of CVD events may weaken with time, the absolute risks associated with a history of pregnancy complications is likely to grow with time since pregnancy, as women age. In addition, we should incorporate pregnancy history data into existing CVD cohorts with decades of followup. By illuminating the timing with which particular CVD risk factors emerge in the wake of specific pregnancy complications, we may be able to leverage the information contained by pregnancy history to predict CVD risk earlier than conventional risk screening protocols.

(b) Importance of linking research across life stages: need for studies with established CVD risk factors measured before, during, and after pregnancy

To understand the trajectory of CVD risk and the role of pregnancy complications in that trajectory, we need more studies to measure CVD risk factors prior to conception, particularly as evidence suggests that changes in blood pressure, augmentation index, and pulse wave velocity occur as early as 6 weeks' gestation, indicating that maternal adaptations occur very early in gestation (Mahendru et al. 2014). This raises the question of whether "booking" first trimester measures that are available in several birth cohorts is representative of prepregnancy values and emphasizes the importance of ascertaining cardiovascular health trajectories from pre- to postpartum.

(c) Need for innovative analytical approaches to improve causal inference

Methods for improving our understanding of whether pregnancy complications are causally related to later maternal health need to go beyond 
conventional multivariable approaches in prospective cohorts. For example, if it is found that genetic variants associated with high blood pressure and glucose intolerance/type 2 diabetes in general populations of men and nonpregnant women are also associated with HDP and GDM, this would lend some support to the hypothesis of a common etiology and pregnancy unmasking a preexisting (genetic) risk. There is some evidence that several type 2 diabetes mellitus variants from genome-wide association studies show robust associations with GDM (Karlsson et al. 2007; Lauenborg et al. 2009; Cho et al. 2009; Kwak et al. 2012).

Although it is not feasible to randomize women to pregnancy complications, long-term follow-up of women who have been in randomized controlled trials that have effectively prevented or treated the pregnancy complication will also address some of the research questions above. Lastly, experimental induction of pregnancy complications in animal models and following the mothers after delivery to examine whether vascular damage was sustained or metabolic risk increased are important for examining the question of a pregnancy causal effect (Bytautiene et al. 2010). However, the generalizability of the animal models depends on the fidelity with which the human pregnancy complications, such as preeclampsia, can be mimicked in other species, where they may not occur naturally.

\subsection{Translational Priorities}

We are just beginning to investigate the clinical implications of this growing body of research. First, we need to establish the role of pregnancy complications in determining maternal chronic disease risk. Independently of that, we also need to determine our ability to change the health trajectories of women with histories of complicated pregnancy. We will then have to consider the many issues of integrating the findings into clinical and public health systems. Some potential clinical implications include the need to link pre- natal with primary care medical records, development of clinical screening strategies, prevention and treatment protocols after pregnancy complications, and increasing awareness among clinicians of these associations that span typical clinical silos between obstetrics and medicine (Rich-Edwards et al. 2010).

\section{Conclusions}

The stress test of pregnancy provides glimpses into the otherwise silent early adult years in which health development and chronic disease trajectories are set. Research to characterize the ways in which pregnancy complications inform us about subclinical and clinical vascular and metabolic risk in the mother is in its infancy. Future research will require large datasets that have prospectively collected accurate data on cardiovascular risk factors before, during, and after pregnancy, into middle age and beyond, when disease begins to emerge; data on pregnancy complications is also required. Only with such detailed information can we determine the extent to which specific pregnancy complications are related to future CVD, over and above prepregnancy risk factors, and whether they add to established risk factor scores calculated in middle age. With large birth cohorts increasingly recognizing the importance of long-term follow-up of the mother as well as their infant, the potential for this research is increasing. Ultimately, randomized controlled trials will be necessary to establish whether pregnancy advice and/or continued monitoring and early treatment of women identified as at risk during pregnancy is a costeffective way of reducing CVD risk in women. Research in this area will require integration across such diverse specialties including obstetrics, primary care, pediatrics, endocrinology, and cardiology. This broader perspective may yield novel insights into the determinants of pregnancy outcomes and health development across the lifespan, perhaps creating a large shift in the ways in which we promote the health of women and children. 


\section{References}

Agatisa, P. K., Ness, R. B., Roberts, J. M., Costantino, J. P., Kuller, L. H., \& McLaughlin, M. K. (2004). Impairment of endothelial function in women with a history of preeclampsia: An indicator of cardiovascular risk. American Journal of Physiology - Heart and Circulatory Physiology, 286, H1389-H1393.

Anastasiou, E., Lekakis, J. P., Alevizaki, M., et al. (1998). Impaired endothelium-dependent vasodilatation in women with previous gestational diabetes. Diabetes Care, 21, 2111-2115.

Beck, S., Wojdyla, D., Say, L., et al. (2010). The worldwide incidence of preterm birth: A systematic review of maternal mortality and morbidity. Bulletin of the World Health Organization, 88, 31-38.

Bellamy, L., Casas, J. P., Hingorani, A. D., \& Williams, D. J. (2007). Pre-eclampsia and risk of cardiovascular disease and cancer in later life: Systematic review and meta-analysis. British Medical Journal, 335, 974.

Bellamy, L., Casas, J. P., Hingorani, A. D., \& Williams, D. (2009). Type 2 diabetes mellitus after gestational diabetes: A systematic review and meta-analysis. Lancet, 373, 1773-1779.

Berends, A. L., de Groot, C. J., Sijbrands, E. J., et al. (2008). Shared constitutional risks for maternal vascular-related pregnancy complications and future cardiovascular disease. Hypertension, 51, 1034-1041.

Bonamy, A. K., Parikh, N. I., Cnattingius, S., Ludvigsson, J. F., \& Ingelsson, E. (2011). Birth characteristics and subsequent risks of maternal cardiovascular disease: Effects of gestational age and fetal growth. Circulation, 124, 2839-2846.

Butte, N. F. (2000). Carbohydrate and lipid metabolism in pregnancy: Normal compared with gestational diabetes mellitus. The American Journal of Clinical Nutrition, 71, 1256S-1261S.

Bytautiene, E., Lu, F., Tamayo, E. H., et al. (2010). Longterm maternal cardiovascular function in a mouse model of sFlt-1-induced preeclampsia. American Journal of Physiology. Heart and Circulatory Physiology, 298, H189-H193.

Campbell, S., Griffin, D. R., Pearce, J. M., et al. (1983). New doppler technique for assessing uteroplacental blood flow. Lancet, 321, 675-677.

Carr, D. B., Utzschneider, K. M., Hull, R. L., et al. (2006). Gestational diabetes mellitus increases the risk of cardiovascular disease in women with a family history of type 2 diabetes. Diabetes Care, 29, 2078-2083.

Catov, J., Newman, A., Roberts, J., et al. (2007a). Association between infant birth weight and maternal cardiovascular risk factors in the health, aging, and body composition study. Annals of Epidemiology, 17, 36-43.

Catov, J. M., Bodnar, L. M., Kip, K. E., et al. (2007b). Early pregnancy lipid concentrations and spontaneous preterm birth. American Journal of Obstetrics and Gynecology, 197, 610. e611-610. e617.
Catov, J. M., Bodnar, L. M., Ness, R. B., Barron, S. J., \& Roberts, J. M. (2007c). Inflammation and dyslipidemia related to risk of spontaneous preterm birth. American Journal of Epidemiology, 166, 1312-1319.

Catov, J. M., Nohr, E. A., Olsen, J., \& Ness, R. B. (2008a). Chronic hypertension related to risk for preterm and term small-for-gestational-age births. Obstetrics and Gynecology, 112, 290.

Catov, J., Bodnar, L., Hackney, D., Roberts, J., \& Simhan, S. (2008b). Activation of the fibrinolytic cascade early in pregnancy among women with spontaneous preterm birth. Obstetrics and Gynecology, $112,1116-1122$

Catov, J. M., Wu, C. S., Olsen, J., Sutton-Tyrrell, K., Li, J., \& Nohr, E. A. (2010a). Early or recurrent preterm birth and maternal cardiovascular disease risk. Annals of Epidemiology, 20, 604-609.

Catov, J. M., Ness, R. B., Wellons, M. F., Jacobs, D. R., Roberts, J. M., \& Gunderson, E. P. (2010b). Prepregnancy lipids related to preterm birth risk: The coronary artery risk development in young adults study. Journal of Clinical Endocrinology and Metabolism, 95, 2009-2028.

Catov, J. M., Dodge, R., Yamal, J. M., Roberts, J. M., Piller, L. B., \& Ness, R. B. (2011). Prior preterm or small-for-gestational-age birth related to maternal metabolic syndrome. Obstetrics and Gynecology, 117, 225-232.

Catov, J. M., Dodge, R., Barinas-Mitchell, E., et al. (2013). Prior preterm birth and maternal subclinical cardiovascular disease 4 to 12 years after pregnancy. Journal of Women's Health, 22(2002), 835-843.

Cho, Y. M., Kim, T. H., Lim, S., et al. (2009). Type 2 diabetes-associated genetic variants discovered in the recent genome-wide association studies are related to gestational diabetes mellitus in the Korean population. Diabetologia, 52, 253-261.

Clausen, T., Djurovic, S., \& Henriksen, T. (2001). Dyslipidemia in early second trimester is mainly a feature of women with early onset pre-eclampsia. BJOG, 108, 1081-1087.

Curry, A., Vogel, I., Drews, C., et al. (2007). Midpregnancy maternal plasma levels of interleukin 2, 6, and 12 , tumor necrosis factor-alpha, interferon-gamma, and granulocyte-macrophage colony-stimulating factor and spontaneous preterm delivery. Acta Obstetricia et Gynecologica Scandinavica, 86, 1103-1110.

Davey Smith, G., Hart, C., Ferrell, C., et al. (1997). Birth weight of offspring and mortality in the Renfrew and Paisley study: Prospective observational study. British Medical Journal, 315, 1189-1193.

Davey Smith, G., Harding, S., \& Rosato, M. (2000a). Relation between infants' birth weight and mothers' mortality: Prospective observational study. British Medical Journal, 320, 839-840.

Davey Smith, G., Whitley, E., Gissler, M., \& Hemminki, E. (2000b). Birth dimensions of offspring, premature birth, and the mortality of mothers. Lancet, 356, 2066-2067. 
Davey Smith, G., Sterne, J., Tynelius, P., Lawlor, D. A., \& Rasmussen, F. (2005). Birth weight of offspring and subsequent cardiovascular mortality of the parents. Epidemiology, 16, 563-569.

Davey Smith, G., Hypponen, E., Power, C., \& Lawlor, D. A. (2007). Offspring birth weight and parental mortality: Prospective observational study and metaanalysis. American Journal of Epidemiology, 166, 160-169.

Dekker, J. M., \& Schouten, E. G. (1993). Number of pregnancies and risk of cardiovascular disease. The New England Journal of Medicine, 329, 1893-1894. author reply $1894-1895$.

Di Cianni, G., Lencioni, C., Volpe, L., et al. (2007). $\mathrm{C}$-reactive protein and metabolic syndrome in women with previous gestational diabetes. Diabetes/ Metabolism Research and Reviews, 23, 135-140.

Ducey, J., Schulman, H., Farmakides, G., et al. (1987). A classification of hypertension in pregnancy based on Doppler velocimetry. American Journal of Obstetrics and Gynecology, 157, 680-685.

Edison, R. J., Berg, K., Remaley, A., et al. (2007). Adverse birth outcome among mothers with low serum cholesterol. Pediatrics, 120, 723-733.

Enquobahrie, D. A., Williams, M. A., Qiu, C., \& Luthy, D. A. (2005). Early pregnancy lipid concentrations and the risk of gestational diabetes mellitus. Diabetes Research and Clinical Practice, 70, 134-142.

Ernst, G. D. S., de Jonge, L. L., Hofman, A., et al. (2011). C-reactive protein levels in early pregnancy, fetal growth patterns, and the risk for neonatal complications: The Generation R Study. American Journal of Obstetrics and Gynecology, 205, 132.e131-132. e112.

Fraser, A., Nelson, S. M., Macdonald-Wallis, C., et al. (2012). Associations of pregnancy complications with calculated cardiovascular disease risk and cardiovascular risk factors in middle age/clinical perspective. Circulation, 125, 1367-1380.

Freathy, R. M., Weedon, M. N., Bennett, A., et al. (2007). Type 2 diabetes TCF7L2 risk genotypes alter birth weight: A study of 24,053 individuals. American Journal of Human Genetics, 80, 1150-1161.

Freeman, D. J., McManus, F., Brown, E. A., et al. (2004). Short-and long-term changes in plasma inflammatory markers associated with preeclampsia. Hypertension, 44, 708-714.

Friedlander, Y., Paltiel, O., Manor, O., et al. (2007). Birthweight of offspring and mortality of parents: The Jerusalem perinatal study cohort. Annals of Epidemiology, 17, 914-922.

Funai, E. F., Friedlander, Y., Paltiel, O., et al. (2005). Longterm mortality after preeclampsia. Epidemiology, 16, 206-215.

Gammill, H. S., Powers, R. W., Clifton, R. G., et al. (2010). Does C-reactive protein predict recurrent preeclampsia? Hypertension in Pregnancy, 29, 399-409.

Girardi, G. (2011). Role of tissue factor in pregnancy complications: Crosstalk between coagulation and inflammation. Thrombosis Research, 127(Suppl 3), S43-S46.

Green, A. B. V., \& Moser, K. (1988). Mortality in women in relation to their childbearing history. BMJ (Clinical research ed), 297, 391-395.

Greenland, P., Alpert, J. S., Beller, G. A., et al. (2010). 2010 ACCF/AHA guideline for assessment of cardiovascular risk in asymptomatic adults: A report of the American College of Cardiology Foundation/ American Heart Association Task Force on Practice Guidelines. Circulation, 122, e584-e636.

Hackney, D. N., Catov, J. M., \& Simhan, H. N. (2010). Low concentrations of thrombin-inhibitor complexes and the risk of preterm delivery. American Journal of Obstetrics and Gynecology, 203, 184.e181-184.e186.

Hannaford, P., Ferry, S., \& Hirsch, S. (1997). Cardiovascular sequelae of toxaemia of pregnancy. Heart, 77, 154-158.

Hastie, C. E., Smith, G. C., MacKay, D. F., \& Pell, J. P. (2011a). Maternal risk of ischaemic heart disease following elective and spontaneous pre-term delivery: Retrospective cohort study of 750350 singleton pregnancies. International Journal of Epidemiology, 40, 914-919.

Hastie, C. E., Smith, G. C. S., Mackay, D. F., \& Pell, J. P. (2011b). Association between preterm delivery and subsequent C-reactive protein: A retrospective cohort study. American Journal of Obstetrics and Gynecology, 205, 556.e551-556.e554.

Hedderson, M. M., Ferrara, A., \& Sacks, D. A. (2003). Gestational diabetes mellitus and lesser degrees of pregnancy hyperglycemia: Association with increased risk of spontaneous preterm birth. Obstetrics and Gynecology, 102, 850-856.

Heilmann, L., Rath, W., \& Pollow, K. (2007). Hemostatic abnormalities in patients with severe preeclampsia. Clinical and Applied Thrombosis/Hemostasis, 13, 285-291.

Heitritter, S. M., Solomon, C. G., Mitchell, G. F., Skali-Ounis, N., \& Seely, E. W. (2005). Subclinical inflammation and vascular dysfunction in women with previous gestational diabetes mellitus. Journal of Clinical Endocrinology and Metabolism, 90, 3983-3988.

Herrera, E. (2000). Metabolic adaptations in pregnancy and their implications for the availability of substrates to the fetus. European Journal of Clinical Nutrition, 54, S47.

Hubel, C. A., McLaughlin, M. K., Evans, R. W., Hauth, B. A., Sims, C. J., \& Roberts, J. M. (1996). Fasting serum triglycerides, free fatty acids, and malondialdehyde are increased in preeclampsia, are positively correlated, and decrease within 48 hours post partum. American Journal of Obstetrics and Gynecology, 174, 975-982.

Hubel, C., Shakir, Y., Gallaher, M., McLaughlin, M., \& Roberts, J. (1998a). Low-density lipoprotein particle size decreases during normal pregnancy in association with triglyceride increases. Journal of the Society for Gynecologic Investigation, 5, 244-250. 
Hubel, C. A., Lyall, F., Weissfeld, L., Gandley, R. E., \& Roberts, J. M. (1998b). Small low-density lipoproteins and vascular cell adhesion molecule-1 are increased in association with hyperlipidemia in preeclampsia. Metabolism, 47, 1281-1288.

Hubel, C. A., Powers, R., Snaedal, S., et al. (2006). $\mathrm{C}$-reactive protein is increased 30 years after eclamptic pregnancy. J Soc Gynecol Invest, 13(2 Suppl), 292A.

Hubel, C. A., Powers, R. W., Snaedal, S., et al. (2008). C-reactive protein is elevated 30 years after eclamptic pregnancy. Hypertension, 51, 1499-1505.

Irgens, H. U., Reisaeter, L., Irgens, L. M., \& Lie, R. T. (2001). Long term mortality of mothers and fathers after pre-eclampsia: Population based cohort study. BMJ (Clinical research ed), 323, 1213-1217.

James-Todd, T. K. A., Hibert, E., Mason, S., Vadnais, M., Hu, F., \& Rich-Edwards. J. (2010). Gestation length, birth weight and subsequent risk of type 2 diabetes in mothers. Oral presentation. Presented at American Diabetes Association's 70th Scientific Sessions, June 2010, Orlando, FL.

Jónsdóttir, L., Arngrimsson, R., Geirsson, R. T., Slgvaldason, H., \& Slgfússon, N. (1995). Death rates from ischemic heart disease in women with a history of hypertension in pregnancy. Acta Obstetricia et Gynecologica Scandinavica, 74, 772-776.

Kanagalingam, M. G., Nelson, S. M., Freeman, D. J., et al. (2009). Vascular dysfunction and alteration of novel and classic cardiovascular risk factors in mothers of growth restricted offspring. Atherosclerosis, 205, 244-250.

Kelly, R., Holzman, C., Senagore, P., et al. (2009). Placental vascular pathology findings and pathways to preterm delivery. American Journal of Epidemiology, 170, 148-158.

Kestenbaum, B., Seliger, S. L., Easterling, T. R., et al. (2003). Cardiovascular and thromboembolic events following hypertensive pregnancy. American Journal of Kidney Diseases, 42, 982-989.

Kim, C., Newton, K. M., \& Knopp, R. H. (2002). Gestational diabetes and the incidence of type 2 diabetes a systematic review. Diabetes Care, 25, 1862-1868.

Kwak, S. H., Kim, S. H., Cho, Y. M., et al. (2012). A genome-wide association study of gestational diabetes mellitus in Korean women. Diabetes, 61, 531-541.

Labarthe, D. R. (1999). Prevention of cardiovascular risk factors in the first place. Preventive Medicine, 29, S72-S78.

Laivuori, H., Tikkanen, M. J., \& Ylikorkala, O. (1996). Hyperinsulinemia 17 years after preeclamptic first pregnancy. The Journal of Clinical Endocrinology and Metabolism, 81, 2908-2911.

Lauenborg, J., Mathiesen, E., Hansen, T., et al. (2005). The prevalence of the metabolic syndrome in a danish population of women with previous gestational diabetes mellitus is three-fold higher than in the general population. The Journal of Clinical Endocrinology and Metabolism, 90, 4004-4010.
Lauenborg, J., Grarup, N., Damm, P., et al. (2009). Common type 2 diabetes risk gene variants associate with gestational diabetes. The Journal of Clinical Endocrinology and Metabolism, 94, 145-150.

Lawlor, D. A., Emberson, J. R., Ebrahim, S., et al. (2003). Is the association between parity and coronary heart disease due to biological effects of pregnancy or adverse lifestyle risk factors associated with child-rearing? Circulation, 107, 1260-1264.

Lawlor, D. A., Relton, C., Sattar, N., \& Nelson, S. M. (2012). Maternal adiposity - a determinant of perinatal and offspring outcomes? Nature Reviews Endocrinology, 8, 679-688.

Lie, R. T., Wilcox, A. J., \& Skjaerven, R. (2006). Maternal and paternal influences on length of pregnancy. Obstetrics and Gynecology, 107, 880-885.

Lin, Y.-S., Tang, C.-H., Yang, C.-Y. C., et al. (2011). Effect of pre-eclampsia-eclampsia on major cardiovascular events among peripartum women in Taiwan. The American Journal of Cardiology, 107, 325-330.

Lykke, J. A., Langhoff-Roos, J., Sibai, B. M., Funai, E. F., Triche, E. W., \& Paidas, M. J. (2009). Hypertensive pregnancy disorders and subsequent cardiovascular morbidity and type 2 diabetes mellitus in the mother. Hypertension, 53, 944-951.

Lykke, J. A., Langhoff-Roos, J., Lockwood, C. J., Triche, E. W., \& Paidas, M. J. (2010a). Mortality of mothers from cardiovascular and non-cardiovascular causes following pregnancy complications in first delivery. Paediatric and Perinatal Epidemiology, 24, 323-330.

Lykke, J., Paidas, M., Damm, P., Triche, E., Kuczynski, E., \& Langhoff-Roos, J. (2010b). Preterm delivery and risk of subsequent cardiovascular morbidity and type-II diabetes in the mother. BJOG: An International Journal of Obstetrics \& Gynaecology, 117, 274-281.

Lykke, J. A., Paidas, M. J., Triche, E. W., \& LANGHOFFROOS, J. (2012). Fetal growth and later maternal death, cardiovascular disease and diabetes. Acta Obstetricia et Gynecologica Scandinavica, 91, 503-510.

Macdonald-Wallis, C., Lawlor, D. A., Fraser, A., May, M., Nelson, S. M., \& Tilling, K. (2012). Blood pressure change in normotensive, gestational hypertensive, preeclamptic, and essential hypertensive pregnancies. Hypertension, 59, 1241-1248.

Magnussen, E. B., Vatten, L. J., Lund-Nilsen, T. I., Salvesen, K. A., Smith, G. D., \& Romundstad, P. R. (2007). Prepregnancy cardiovascular risk factors as predictors of pre-eclampsia: Population based cohort study. BMJ (Clinical research ed), 335, 978.

Magnussen, E. B., Vatten, L. J., Smith, G. D., \& Romundstad, P. R. (2009). Hypertensive disorders in pregnancy and subsequently measured cardiovascular risk factors. Obstetrics and Gynecology, 114, 961-970.

Magnussen, E. B., Vatten, L. J., Myklestad, K., Salvesen, K. Å., \& Romundstad, P. R. (2011). Cardiovascular risk factors prior to conception and the length of 
pregnancy: Population-based cohort study. American Journal of Obstetrics and Gynecology, 204, 526. e521-526.e528.

Mahendru, A. A., Everett, T. R., Wilkinson, I. B., Lees, C. C., \& McEniery, C. M. (2014). A longitudinal study of maternal cardiovascular function from preconception to the postpartum period. Journal of Hypertension, 32, 849-856.

Manten, G. T., Sikkema, M. J., Voorbij, H. A., Visser, G. H., Bruinse, H. W., \& Franx, A. (2007). Risk factors for cardiovascular disease in women with a history of pregnancy complicated by preeclampsia or intrauterine growth restriction. Hypertension in Pregnancy, 26, $39-50$.

Martinez, G., Daniels, K., \& Chandra, A. (2012). Fertility of men and women aged 15-44 years in the United States: National survey of family growth, 2006-2010. Natl Health Stat Report, 12, 1-28.

Mathers, C., Boerma, J. T., Fat, D. M., \& World Health Organization. (2008). The global burden of disease : 2004 update. Geneva: World Health Organization.

McDonald, S. D., Malinowski, A., Zhou, Q., Yusuf, S., \& Devereaux, P. J. (2008). Cardiovascular sequelae of preeclampsia/eclampsia: A systematic review and meta-analyses. American Heart Journal, 156, 918-930.

Metzger, B. E., Cho, N. H., Roston, S. M., \& Radvany, R. (1993). Prepregnancy weight and antepartum insulin secretion predict glucose tolerance five years after gestational diabetes mellitus. Diabetes Care, 16(1wik), 42-1605.

Meyers-Seifer, C. H., \& Vohr, B. R. (1996). Lipid levels in former gestational diabetic mothers. Diabetes Care, 19, 1351-1356.

MMWR. (1989). Chronic disease reports in the Morbidity and Mortality Weekly Report (MMWR). MMWR Morb Mortal Wkly Rep, 38, 1-8.

Monga, M., \& Creasy, R. (1994). Cardiovascular and renal adaptation to pregnancy. In R. Creasy, R. Resnik, J. D. Iams, et al. (Eds.), Maternal-fetal medicine: Principles and practice (pp. 758-767). Philadelphia: WB Saunders.

Mongraw-Chaffin, M. L., Cirillo, P. M., \& Cohn, B. A. (2010). Preeclampsia and cardiovascular disease death. Hypertension, 56, 166-171.

Mosca, L., Benjamin, E. J., Berra, K., et al. (2011). Effectiveness-based guidelines for the prevention of cardiovascular disease in women - 2011 update: A guideline from the american heart association. Circulation, 123, 1243-1262.

Nanda, S. S. M., Syngelaki, A., Akolekar, R., \& Nicolaides, K. H. (2011). Prediction of gestational diabetes mellitus by maternal factors and biomarkers at 11 to 13 weeks. Prenatal Diagnosis, 31, 135-141.

Nardi, O., Zureik, M., Courbon, D., Ducimetière, P., \& Clavel-Chapelon, F. (2006). Preterm delivery of a first child and subsequent mothers' risk of ischaemic heart disease: A nested case-control study. European Journal of Cardiovascular Prevention \& Rehabilitation, 13, 281-283.
Ness, R. B., Harris, T., Cobb, J., et al. (1993). Number of pregnancies and the subsequent risk of cardiovascular disease. The New England Journal of Medicine, 328, $1528-1533$.

Ness, R. B., Cobb, J., Harm, T., \& D’Agostino, R. B. (1995). Does number of children increase the rate of coronary heart disease in men? Epidemiology, 6, $442-445$.

North, R. A., McCowan, L. M., Dekker, G. A., et al. (2011). Clinical risk prediction for pre-eclampsia in nulliparous women: Development of model in international prospective cohort. BMJ (Clinical research ed), 342, d1875.

O'Brien, T. E., Ray, J. G., \& Chan, W. S. (2003). Maternal body mass index and the risk of preeclampsia: A systematic overview. Epidemiology, 14, 368-374.

Oblast, T. I. (1999). Decline in deaths from heart disease and stroke - United States, 1900-1999. Heart Disease and Stroke, 63(1900), 593-597.

OECD Family D. (2014). Childlessness (SF 2.5) In: Social Policy Division, Organisation for Economic Co-operation and Development. Paris, France: 2010. SF2.5 report on childlessness. www.oecd.org/social/ family/database. Accessed 24 June, 2013.

Ostlund, I., Haglund, B., \& Hanson, U. (2004). Gestational diabetes and preeclampsia. European Journal of Obstetrics, Gynecology, and Reproductive Biology, $113,12-16$.

Parikh, N. I., Cnattingius, S., Dickman, P. W., Mittleman, M. A., Ludvigsson, J. F., \& Ingelsson, E. (2010). Parity and risk of later-life maternal cardiovascular disease. American Heart Journal, 159, 215-221. e216.

Pell, J. P., Smith, G. C., \& Walsh, D. (2004). Pregnancy complications and subsequent maternal cerebrovascular events: A retrospective cohort study of 119,668 births. American Journal of Epidemiology, 159, 336-342.

Pitiphat, W., Gillman, M. W., Joshipura, K. J., Williams, P. L., Douglass, C. W., \& Rich-Edwards, J. W. (2005). Plasma C-reactive protein in early pregnancy and preterm delivery. American Journal of Epidemiology, 162, 1108-1113.

Portelinha, A., Cerdeira, A. S., Belo, L., et al. (2009). Haemostatic factors in women with history of Preeclampsia. Thrombosis Research, 124, 52-56.

Qiu, C., Williams, M. A., Leisenring, W. M., et al. (2003). Family history of hypertension and type 2 diabetes in relation to preeclampsia risk. Hypertension, 41, 408-413.

Regitz-Zagrosek, V., Lundqvist, C. B., Borghi, C., et al. (2011). ESC Guidelines on the management of cardiovascular diseases during pregnancy. The Task Force on the Management of Cardiovascular Diseases during Pregnancy of the European Society of Cardiology (ESC). European Heart Journal, 32, 3147-3197.

Retnakaran, R., \& Shah, B. R. (2009a). Abnormal screening glucose challenge test in pregnancy and future risk of diabetes in young women. Diabetic Medicine, 26, 474-477. 
Retnakaran, R., \& Shah, B. R. (2009b). Mild glucose intolerance in pregnancy and risk of cardiovascular disease: A population-based cohort study. Canadian Medical Association Journal, 181, 371-376.

Retnakaran, R., Austin, P. C., \& Shah, B. R. (2011). Effect of subsequent pregnancies on the risk of developing diabetes following a first pregnancy complicated by gestational diabetes: A population-based study. Diabetic Medicine, 28, 287-292.

Rich-Edwards, J. W. (2009). Reproductive health as a sentinel of chronic disease in women. Women's Health (London, England), 5, 101-105.

Rich-Edwards, J. W., McElrath, T. F., Karumanchi, S. A., \& Seely, E. W. (2010). Breathing life into the lifecourse approach: Pregnancy history and cardiovascular disease in women. Hypertension, 56, 331-334.

Rich-Edwards, J. W. K. K., Wilcox, A., \& Skjaerven, R. (2012). Duration of first pregnancy predicts maternal cardiovascular death, whether delivery was medically indicated or spontaneous. American Journal of Epidemiology, 175(Suppl 11), S64.

Rich-Edwards, J. W., Fraser, A., Lawlor, D. A., \& Catov, J. M. (2014). Pregnancy characteristics and women's future cardiovascular health: An underused opportunity to improve women's health? Epidemiologic Reviews, 36, 57-70.

Riskin-Mashiah, S., Damti, A., Younes, G., \& Auslender, R. (2010). First trimester fasting hyperglycemia as a predictor for the development of gestational diabetes mellitus. European Journal of Obstetrics, Gynecology, and Reproductive Biology, 152, 163-167.

Roberts, C. L., Algert, C. S., Morris, J. M., Ford, J. B., \& Henderson-Smart, D. J. (2005). Hypertensive disorders in pregnancy: A population-based study. The Medical Journal of Australia, 182, 332-335.

Romero, R., Espinoza, J., Gonçalves, L. F., Kusanovic, J. P., Friel, L., \& Hassan, S. (2007). The role of inflammation and infection in preterm birth. Seminars in Reproductive Medicine, 25, 021-039.

Romundstad, P. R., Davey Smith, G., Nilsen, T. I., \& Vatten, L. J. (2007). Associations of prepregnancy cardiovascular risk factors with the offspring's birth weight. American Journal of Epidemiology, 166, 1359-1364.

Romundstad, P. R., Magnussen, E. B., Smith, G. D., \& Vatten, L. J. (2010). Hypertension in pregnancy and later cardiovascular risk: Common antecedents? Circulation, 122, 579-584.

Sacks DA, C. W., Wolde-Tsadik, G., \& Buchanan, T. A. (2003). Fasting plasma glucose test at the first prenatal visit as a screen for gestational diabetes. Obstetrics and Gynecology, 101, 1197-1203.

Sarwar, N., Gao, P., Seshasai, S. R., et al. (2010). Diabetes mellitus, fasting blood glucose concentration, and risk of vascular disease: A collaborative meta-analysis of 102 prospective studies. Lancet, 375, 2215-2222.

Sattar, N. (2004). Do pregnancy complications and CVD share common antecedents? Atherosclerosis Supplements, 5, 3-7.
Sattar, N., \& Greer, I. A. (2002). Pregnancy complications and maternal cardiovascular risk: Opportunities for intervention and screening? British Medical Journal, $325,157-160$.

Sattar, N., Bendomir, A., Berry, C., Shepherd, J., Greer, I. A., \& Packard, C. J. (1997). Lipoprotein subfraction concentrations in preeclampsia: Pathogenic parallels to atherosclerosis. Obstetrics and Gynecology, 89, 403-408.

Sattar, N., Greer, I., Galloway, P., et al. (1999). Lipid and lipoprotein concentrations in pregnancies complicated by intrauterine growth restriction. Journal of Clinical Endocrinology and Metabolism, 84, 128-130.

Sattar, N., Ramsay, J., Crawford, L., Cheyne, H., \& Greer, I. A. (2003). Classic and novel risk factor parameters in women with a history of preeclampsia. Hypertension, 42, 39-42.

Savvidou, M. D., Hingorani, A. D., Tsikas, D., Frölich, J. C., Vallance, P., \& Nicolaides, K. H. (2003). Endothelial dysfunction and raised plasma concentrations of asymmetric dimethylarginine in pregnant women who subsequently develop pre-eclampsia. The Lancet, 361, 1511-1517.

Savvidou, M. D., Kaihura, C., Anderson, J. M., \& Nicolaides, K. H. (2011). Maternal arterial stiffness in women who subsequently develop pre-eclampsia. PLOS ONE, 6, e18703.

Scarborough, P., \& Weissberg, P. (2011). Trends in coronary heart disease, 1961-2011. London: British Heart Foundation.

Schwarz, E. B., Ray, R. M., Stuebe, A. M., et al. (2009). Duration of lactation and risk factors for maternal cardiovascular disease. Obstetrics and Gynecology, 113, 974-982.

Shaat, N. L. A., Karlsson, E., Ivarsson, S., Parikh, H., Berntorp, K., \& Groop, L. (2007). A variant in the transcription factor 7-like 2 (TCF7L2) gene is associated with an increased risk of gestational diabetes mellitus. Diabetologia, 50, 972-979.

Shah, B. R., Retnakaran, R., \& Booth, G. L. (2008). Increased risk of cardiovascular disease in young women following gestational diabetes mellitus. Diabetes Care, 31, 1668-1669.

Shah, R. U., Klein, L., \& Lloyd-Jones, D. M. (2009). Heart failure in women: Epidemiology, biology and treatment. Women's Health (London, England), 5, 517-527.

Shaw, L. J., Bairey Merz, C. N., Pepine, C. J., et al. (2006). Insights from the NHLBI-Sponsored Women's Ischemia Syndrome Evaluation (WISE) Study: Part I: Gender differences in traditional and novel risk factors, symptom evaluation, and gender-optimized diagnostic strategies. Journal of the American College of Cardiology, 47, S4-S20.

Shay, C. M., Ning, H., Allen, N. B., et al. (2012). Status of cardiovascular health in US adults clinical perspective prevalence estimates from the National Health and Nutrition Examination Surveys (NHANES) 20032008. Circulation, 125, 45-56.

Skjaerven, R., Wilcox, A. J., Klungsoyr, K., et al. (2012). Cardiovascular mortality after pre-eclampsia in one 
child mothers: Prospective, population based cohort study. BMJ (Clinical research ed), 345, e7677.

Smith, G. C., Pell, J. P., \& Walsh, D. (2001). Pregnancy complications and maternal risk of ischaemic heart disease: A retrospective cohort study of 129,290 births. Lancet, 357, 2002-2006.

Smith, G. C. S., Shah, I., Pell, J. P., Crossley, J. A., \& Dobbie, R. (2007). Maternal obesity in early pregnancy and risk of spontaneous and elective preterm deliveries: A retrospective cohort study. American Journal of Public Health, 97, 157-162.

Smith, G. N., Walker, M. C., Liu, A., et al. (2009). A history of preeclampsia identifies women who have underlying cardiovascular risk factors. American Journal of Obstetrics and Gynecology, 200(58), e51-e58.

Solomon, C. G., Willett, W. C., Carey, V. J., et al. (1997). A prospective study of pregravid determinants of gestational diabetes mellitus. JAMA, 278, 1078-1083.

Steenland, K., Lally, C., \& Thun, M. (1996). Parity and coronary heart disease among women in the American Cancer Society CPS II population. Epidemiology, 7, 641-643.

Stepan, H., Faber, R., \& Walther, T. (1999). Expression of low density lipoprotein receptor messenger ribonucleic acid in placentas from pregnancies with intrauterine growth retardation. British Journal of Obstetrics and Gynaecology, 106, 1221-1222.

Tarim, E., Yigit, F., Kilicdag, E., et al. (2006). Early onset of subclinical atherosclerosis in women with gestational diabetes mellitus. Ultrasound in Obstetrics \& Gynecology, 27, 177-182.

United Nations DoEaSA, Population Division. (2009). World fertility report. New York: United Nations Publications.

Verma, A., Boney, C. M., Tucker, R., \& Vohr, B. R. (2002). Insulin resistance syndrome in women with prior history of gestational diabetes mellitus. The Journal of Clinical Endocrinology and Metabolism, 87, 3227-3235.

Wadsack, C., Tabano, S., Maier, A., et al. (2007). Intrauterine growth restriction is associated with alterations in placental lipoprotein receptors and maternal lipoprotein composition. American Journal of Physiology - Endocrinology and Metabolism, 292, E476-E484.
Wallis, A. B., Saftlas, A. F., Hsia, J., \& Atrash, H. K. (2008). Secular trends in the rates of preeclampsia, eclampsia, and gestational hypertension, United States, 1987-2004. American Journal of Hypertension, 21, 521-526.

Weintraub, W. S., Daniels, S. R., Burke, L. E., et al. (2011). Value of primordial and primary prevention for cardiovascular disease: A policy statement from the American Heart Association. Circulation, 124, 967-990.

Wikström, A. K., Haglund, B., Olovsson, M., \& Lindeberg, S. N. (2005). The risk of maternal ischaemic heart disease after gestational hypertensive disease. BJOG: An International Journal of Obstetrics \& Gynaecology, 112, 1486-1491.

Wilcox, A. J., Skjaerven, R., \& Lie, R. T. (2008). Familial patterns of preterm delivery: Maternal and fetal contributions. American Journal of Epidemiology, 167, 474-479.

Williams, M. A., Qiu, C., Muy-Rivera, M., Vadachkoria, S., Song, T., \& Luthy, D. A. (2004). Plasma adiponectin concentrations in early pregnancy and subsequent risk of gestational diabetes mellitus. The Journal of Clinical Endocrinology and Metabolism, 89, 2306-2311.

Wilson, B. J., Watson, M. S., Prescott, G. J., et al. (2003). Hypertensive diseases of pregnancy and risk of hypertension and stroke in later life: Results from cohort study. British Medical Journal, 326, 845.

Winzer, C., Wagner, O., Festa, A., et al. (2004). Plasma adiponectin, insulin sensitivity, and subclinical inflammation in women with prior gestational diabetes mellitus. Diabetes Care, 27, 1721-1727.

Wolf, M., Kettyle, E., Sandler, L., Ecker, J. L., Roberts, J., \& Thadhani, R. (2001). Obesity and preeclampsia: The potential role of inflammation. Obstetrics and Gynecology, 98, 757-762.

Wolf, M., Hubel, C. A., Lam, C., et al. (2004). Preeclampsia and future cardiovascular disease: Potential role of altered angiogenesis and insulin resistance. The Journal of Clinical Endocrinology and Metabolism, 89, 6239-6243.

Yusuf, S., Reddy, S., Ôunpuu, S., \& Anand, S. (2001). Global burden of cardiovascular diseases. Circulation, 104, 2746-2753.

Open Access This chapter is licensed under the terms of the Creative Commons Attribution 4.0 International License (http://creativecommons.org/licenses/by/4.0/), which permits use, sharing, adaptation, distribution and reproduction in any medium or format, as long as you give appropriate credit to the original author(s) and the source, provide a link to the Creative Commons license and indicate if changes were made.

The images or other third party material in this chapter are included in the chapter's Creative Commons license, unless indicated otherwise in a credit line to the material. If material is not included in the chapter's Creative Commons license and your intended use is not permitted by statutory regulation or exceeds the permitted use, you will need to obtain permission directly from the copyright holder. 